\title{
Prensa, política y sociedad: Publicaciones republicanas en Castellón durante el Sexenio Democrático (1868-1873)
}

\author{
Esther PALlardó PARdo \\ Universitat Jaume I de Castellón
}

\begin{abstract}
Resumen:
Este trabajo nace con el objetivo de realizar una aproximación al origen de la prensa de partido en la provincia de Castellón, y tras la curiosidad suscitada por un período histórico, caracterizado por importantes conquistas políticas que, pasando por distintas épocas, han perdurado hasta la actualidad.

Esta investigación nace de la necesidad de conocer mejor el período histórico en el que se sentaron las bases de un incipiente sistema democrático, que ha ido consolidándose con los años. Y de conocer cómo esa realidad -de gran virulencia y convulsión política y social- era transmitida en letra de molde.
\end{abstract}

Palabras clave: Prensa, Política, Sociedad, Sexenio Democrático, Castellón..

\section{Newspapers, politics and society: Republican Publications in Castellón during the Democratic Sexenio (1868-1873)}

\begin{abstract}
:
This work was created with the aim of carrying out an approach to the origin of the party press in the province of Castellón, after the curiosity aroused by a historical period characterized by important political conquests.

This research stems from the need to better understand the historical period in which the foundations of a nascent democratic system, which has been consolidated over the years. And to know how that reality was transmitted by the newspapers.
\end{abstract}

Key Words: Press, Politics, Society, Democratic Sexenio, Castellón.

\section{Referencia normalizada:}

Pallardó Pardo, E. (2014): Prensa, política y sociedad: Publicaciones republicanas en Castellón durante el Sexenio Democrático (1868-1873) Historia y Comunicación Social. Vol. 19. Núm. Especial Enero. Págs. 475-489.

Sumario: 1. Introducción: La prensa de partido tiene su origen en el Sexenio Democrático (1868-1874) y supone la entrada del pueblo en la vida política activa. 2. Simbiosis entre el diario y el partido político. 2.1. El periódico como órgano de expresión del partido político. 2.2. Partido contra partido. Periódico contra periódico. 3. El periódico republicano, máximo exponente de la prensa de partido. 4. Las publicaciones periódicas suplen las aspiraciones políticas. 5. El periódico: él y sus circunstancias. Historia de la aparición y desaparición de la prensa. 6. Conclusiones. 7. Bibliografía. 


\section{Introducción: La prensa de partido tiene su origen en el Sexenio Democrático (1868-1874) y supone la entrada del pueblo en la vida política activa.}

Este trabajo nace con el objetivo de realizar una aproximación al origen de la prensa de partido en la provincia de Castellón, y tras la curiosidad suscitada por un período histórico, caracterizado por importantes conquistas políticas que, pasando por distintas épocas, han perdurado hasta la actualidad.

La consideración de un período político apasionante justifica esta investigación, donde se realiza un estudio de las publicaciones periódicas, especialmente las de tendencia republicana, y su simbiosis con los partidos políticos.

Período político en el que surgieron cuestiones influyentes para consolidar un sistema democrático. Se produjo la conquista de buena parte de los derechos y libertades del sistema político actual, como el sufragio universal, los derechos de libertad, de asociación o de reunión.

Los pocos análisis realizados sobre las publicaciones periódicas que se publicaron entre 1868 y 1874 suscitan una necesidad de plasmar en papel aquellas informaciones, opiniones, aportaciones y experiencias que en torno a este período histórico y a estas publicaciones aparecieron y que son fundamentales para apreciar la evolución histórica en el ámbito político, periodístico y ciudadano.

La letra de molde es un medio convencional que, hasta hace relativamente poco, se consideraba el único medio de comunicación, con unas características concretas que le confieren su particular importancia como correa de transmisión hacia la sociedad. Todavía en la actualidad, si bien se produce la convivencia del tradicional periódico -ahora diario en la mayoría de los casos- con otros medios de comunicación cuya modernización y diversificación ha llegado a límites insospechados.

Así mismo, se analiza la primera Constitución Democrática, que compiló muchos derechos y libertades hoy ya normalmente asumidos, y las continuas batallas que tuvieron que librar políticos que nos precedieron en aras a conseguir mayores cotas de libertad.

Atendiendo a las notables expectativas de una época donde por primera vez se instaura una monarquía democrática parlamentaria, una soberanía nacional, un sufragio universal de varones mayores de 25 años, una declaración de derechos como el de voto, la libertad de residencia, de enseñanza de expresión, de reunión, la regulación de ayuntamientos y diputaciones mediante elección de concejales por sufragio y la de alcaldes entre los concejales o la libertad de cultos.

Esta investigación nace de la necesidad de conocer mejor el período histórico en el que se sentaron las bases de un incipiente sistema democrático, que ha ido consolidándose con los años. Y de conocer cómo esa realidad -de gran virulencia y convulsión política y social- era transmitida en letra de molde. 


\section{Simbiosis entre el diario y el partido político}

El origen de la prensa de partido lo situamos durante el Sexenio Revolucionario (prensa de partido claramente imbricada con los partidos políticos que florecen por doquier en esta época). Un escenario en el que periódico y partido político son la misma cosa; el primero es el canal de expresión, el conducto para transmitir un ideario, una doctrina política sí, pero de partido. A medida que se profundiza en el análisis de la prensa, las hipótesis van cobrando vida propia. El análisis de las publicaciones y de la época histórica, de fuerte convulsión política, van confirmando todas las hipótesis planteadas.

Todo lo que ocurría en las Cortes, en el seno de las asociaciones políticas, en las calles, en las tertulias... era vociferado en y por los periódicos, que pervivían en la calle lo mismo que pervivían los partidos políticos del cual eran órgano de expresión.

Quienes utilizaban la letra de molde para expresarse eran los políticos que estaban al frente de los partidos políticos que nacen en esa época. El periódico se concibe como instrumento de acción política y social, con tendencia a cambiar las circunstancias políticas existentes, con ánimo de influir en los acontecimientos. La proliferación de periódicos es tanta como la de partidos políticos.

\subsection{El periódico como órgano de expresión del partido político}

"Tan solo con el objeto de propaganda y organización, se ha fundado por el comité, este periodico órgano del mismo, en el cual, además de los artículos doctrinales, publicará todas las circulares oficiales del partido: formularios y cuanto convenga para la mejor marcha de los comités". (Piqueras, J. A. La Revolución Democrática, pág 19). Es lo que puede leerse en uno de los periódicos que surgieron en el Sexenio; en una cabecera y en una fecha: El Centinela Federal, en el número publicado en septiembre de 1871. El periódico define lo que fue el espíritu de la prensa durante el Sexenio Lo expresa ya en el primer número que sale a la calle y lo firma el presidente del comité provincial Francisco González Cherma.

Es la prensa de partido. Periódicos que salen a la calle con el único objetivo de crear estados de opinión, de movilizar, de ganar adeptos y sumar votos, en el incipiente contexto democrático de la época. Periódicos que instan al lector a que participe en el marco político caracterizado por la existencia de numerosas agrupaciones políticas, escisiones, fusiones, divisiones... Es época de acuerdos y desacuerdos, de frustraciones políticas y de libertades soñadas. Sumar votos. Sólo dos palabras sintetizan una de las conquistas más importantes de la era democrática. Es en 1868 cuando se produce el último intento de verificar la revolución democrático-burguesa ${ }^{1}$.

En esta amalgama de propósitos se enmarca la tendencia de la prensa de hacer de punta de lanza para herir las reminiscencias del sistema feudal. Es la época que se inicia con la Revolución de 1868, la Gloriosa, que provocó una explosión de publicaciones y abrió las puertas a los periódico declaradamente de partido. La falta de crítica de los diarios de la época isabelina contrastó con la prensa del Sexenio, que 
nacen de forma exclusiva como órgano de expresión de una agrupación política. La prensa de partido nació con el Sexenio aunque la información política ya había salido a la calle entre 1848 y 1856 en forma de hojas sueltas, papeles y proclamas que eran pregonadas por los ciegos de la ciudad.

Pero pese al sentir político que se ponía de manifiesto en estas hojas sueltas no se concebían como voceros de ninguna agrupación política y, por supuesto, no nacían como órganos difusores. La diferencia entre prensa de partido e información política estriba en que la primera nace, de forma exclusiva, para servir los intereses de un grupo político como actor social y parte activa en la sociedad. El periódico asiste a la constitución del partido y el partido se vale del periódico para dar a conocer desde su formación como tal, los miembros que la integran y las reuniones y posiciones internas. La prensa está presente en la propia génesis del partido y recoge fielmente el ideario político de la agrupación de la que es portavoz.

Así pues cuando el partido Democrático Republicano Federal todavía se está gestando, ya se están designando los cargos representativos y se están estableciendo las pautas de actuación, pero el partido ya tiene portavoz. Así se explica en el primer número de La Protesta en mayo de 1871.

Los representantes de quienes aspiran a la República proponen la organización del partido en la misma medida que proponen la propaganda de los principios que rigen al mismo.

Con el Bienio Progresista (1854-1856) se consiguen mayores cotas de libertad que posibilitan el desarrollo de la actividad periodística frente a la carencia de crítica que caracterizaba a los gobiernos moderados de la anterior década. Aún con ello, no surge en Castellón publicación alguna que se erija en portavoz de las agrupaciones políticas existentes. No ocurrirá hasta entrada la revolución septembrina, a finales de 1868 principios de 1869, cuando la Gloriosa trae consigo la proliferación de publicaciones políticas por excelencia y, especialmente, de partido.

En ningún momento con anterioridad al Sexenio, prensa y política salen a la calle tan inseparablemente unidas, ni los periódicos son y sólo son voceros de las ideas de los partidos políticos.

El Sexenio significó la ruptura de la tendencia de la prensa hasta entonces y la apertura a una nueva concepción de las publicaciones periódicas, que ya no tendría marcha atrás. El carácter apolítico y literario de la época anterior al Sexenio dio paso a la prensa de partido en la medida en que las restricciones políticas imperantes en la década ominosa dieron paso a mayores cotas de libertad conquistadas con la Revolución. La intencionalidad política de la prensa en la segunda mitad del siglo XIX está servida. La proliferación de las publicaciones coincide con la constitución y el desarrollo de los partidos políticos. Con la libertad de expresión, la función de la prensa periódica durante la segunda mitad del XIX es decisiva, forjando opinión, cambiándola o consolidando una ya formada. La vida política se caracteriza por el importante incremento de partidos. La Revolución siembra lo que en años posteriores 
inmediatos será una explosión periodística, pero los criterios unitarios duran poco y surge la diferenciación en el seno de los partidos; como consecuencia, la proliferación de partidos políticos $\mathrm{y}$, por consiguiente, la de publicaciones impresas como órganos de expresión de los mismos.

La multiplicidad de partidos supone la multiplicidad de periódicos. La correlación es clara: a más grupos políticos, más publicaciones impresas. Es sobre todo a partir de 1870, año en que existen más de 30 partidos políticos, cuando se produce el apogeo de la prensa de partido. La corta vigencia de los periódicos pone de manifiesto la enorme efervescencia política y/o viceversa. El debate ideológico está en la tribuna y está en la calle.

Los periódicos permiten la aproximación al ciudadano de los debates en las Cámaras, de los principios internacionalistas, de las realidades nacional y local en una combinación de propaganda política, de reivindicación de libertades y derechos, de principios democráticos y máximas revolucionarias. En esta línea, puede afirmarse que a más publicaciones de una tendencia política, más fuerza y más posibilidad de convencer a los ciudadanos de los principios políticos de la misma.

Septiembre de 1873 es también un mes clave para la prensa obrera del siglo XIX en Castellón por la aparición del periódico El Obrero Católico, que se publicó hasta julio de 1897 y que fue el órgano de expresión de la Asamblea de Obreros Católicos.

\subsection{Partido contra partido. Periódico contra periódico}

En una época de fuertes convulsiones políticas, cambios, conquistas, reivindicaciones...los periódicos salen a la calle y se retiran a medida que aparecen y desparecen las agrupaciones políticas. Muchas de las personas que defienden en los clubes y en los comités las ideas políticas de un partido son quienes dirigen y/o participan en la prensa, son el motor activo de las publicaciones periódicas y quienes la conceptúan como un elemento más de difusión de ideas políticas. Un ejemplo: Francisco González Chermá presidió el Comité Republicano de la provincia, fue miembro destacado del partido republicano castellonense, alcalde de Castellón en los primeros años del Sexenio, miembro de la Junta Revolucionaria de Castellón, defensor a ultranza de los principios democráticos en clubes y comités. Además, y no es casualidad, director de El Centinela Federal, en el que constantemente se realiza una aproximación a la figura de González Chermá como persona, como director del periódico y como cabecilla del partido republicano democrático federal.

Las batallas y rencillas políticas se libraban en los periódicos; estaban en la calle, en los clubes, en los comités de partido...la política sale del seno de las agrupaciones y se instala en los periódicos, al alcance de todos los ciudadanos que dispusiesen de 400 milésimas al mes, de 2 reales a la semana, de 75 céntimos al mes o de un real y medio a la semana, según periódicos y según época. Las batallas políticas eran caldo de cultivo en la prensa periódica y los redactores de una publicación de una opción política determinada llenaban hojas y hojas lidiando con los de publicaciones de tendencias opuestas. Algunos ejemplos: 
La batalla dialéctica entre El Radical y el Verderol a finales del año 69 y principios de los 70 está servida. Son quienes están detrás de los mencionados periodicos oponentes políticos, y luchan en la política y en la prensa; en la prensa y en la política. La historia se repite. El Centinela Federal y El Batallador lidiarán con papel y tinta a finales de 1871 y principios del 72. Lucha también entre La Protesta y El Farol. En los últimos números publicados, La Protesta mantiene una batalla dialéctica continua con el periódico unionista El Farol.

La existencia de un diario no tiene sentido sino sale a la calle dispuesto al combate político.

En este período si un periódico no era órgano de expresión de un partido, no estaba considerado prensa de referencia.

\section{El periódico republicano, máximo exponente de la prensa de partido}

La competencia y la rivalidad entre los periódicos es política. El objetivo de las publicaciones partidistas es vender ejemplares para obtener más votos, más respaldo de los ciudadanos; en definitiva, para competir políticamente.

Junto a la declaración de intenciones de un periódico, el programa político de un partido.

La Protesta nace con el objetivo de fomentar las ideas del Partido Democrático Republicano Federal y con la declaración de intenciones de la publicación, el ideario político: desaparición de las quintas; constitución democrática republicana federal; implantación de la ley del jurado; división territorial en lo político, administrativo, militar y judicial; creación de una ley de organización del partido para evitar anomalías en la elección de representantes para comités locales, de partido, provinciales, pactos y asambleas y la defensa de todo tipo de libertades ${ }^{2}$.

La politización del periódico republicano y su posicionamiento político se evidencia en el interés de los redactores, y en la línea editorial de la publicación por difundir las ideas democráticas. La letra de molde es una forma más de hacer política, por lo que desde las páginas del periódico se aboga por los derechos individuales, por la descentralización, por el fin de los privilegios y por las libertades, entre otras máximas revolucionarias. Desde la prensa política afiliada al partido republicano se apuesta por el fin de la desigualdad social, por las libertades, por la revolución; el periódico es elemento activo, un medio para conseguir un fin: el republicano. Prensa y política; política y prensa. La simbiosis viene dada por origen, por definición y por personajes protagonistas. El periódico republicano nace político y se erige como fustigador de las desigualdades y de la maldad social y lo hace desde la propaganda política, desde la utilización del papel y la tinta como portavoces de las ideas republicanas.

Los objetivos planteados por La Protesta son claros: hacer frente a un gobierno monárquico liberal demócrata y presentar una alternativa a la monarquía, la procla- 
mación de la República. El Centinela Federal es el periódico creado por el comité del partido republicano federal.

Nuevamente el planteamiento de la publicación periódica es político; objetivos de El Centinela Federal: dar a conocer, predicar, defender, difundir, propagar los principios del Partido Republicano Democrático Federal.

En el panorama periodístico son fundamentalmente los diarios republicanos, en los que se cuestionan los planteamientos del orden establecido. En los que asoma la revolución social. El ideario político se expone también en los periódicos que no son republicanos, y que están afiliados a otras tendencias políticas y son voceros de otros partidos políticos. La Justicia sienta también las bases de lo que será su andadura en las primeras líneas del primer número de la publicación. En esta ocasión, el periódico nace como portavoz del Partido Radical castellonense y se erige como defensor de las ideas liberales-democrático monárquicas ${ }^{3}$.

La competencia entre los periódicos de la época es política, cada tendencia política dispone de su medio difusor y cada periódico está respaldado por un partido político. Y en el escenario político y periodístico, los personajes son lo mismo: políticos y periodistas, periodistas y políticas.

\section{Las publicaciones periódicas suplen las aspiraciones políticas}

El republicanismo federal castellonense puso de manifiesto desde los primeros años del Sexenio Revolucionario sus aspiraciones políticas a través de las publicaciones La Propaganda y El Cantón Castellonense en 1869, y de las cabeceras La Protesta y El Centinela Federal, que salieron a la calle desde el año 70 al 73 . En el ámbito periodístico, el republicanismo federal estaba dividido en dos ramas. Por una parte, La Propaganda en la que confluyeron periodistas que escribieron en El Progreso Castellonense, dirigido por Manuel V. Masip y Manuel Blasco Oliver y en La Voz del Pueblo, que contó con la firma de Teodoro Tena y Vicente Remolar; ambas publicaciones se identificaban al inicio del Sexenio como de tendencia liberal. La Propaganda tuvo su continuidad en La Protesta, que sale a la calle en mayo de 1871 y se prolonga hasta noviembre del mismo año.

Por otra parte, el sucesor de El Legos, El Centinela Federal, se publicó bajo la dirección de Francisco González Chermá, desde septiembre de 1871 hasta mayo de $1872^{4}$.

Identifiquemos cada uno de los diarios y cada una de las facciones del republicanismo.

La Protesta se imprimía en las instalaciones de Civera y Armengol, ubicadas la calle Sabaters, imprenta de donde salieron buena parte de los diarios publicados durante el Sexenio, de diversa tendencia política; desde publicaciones carlistas hasta 
publicaciones republicanas pasando por diarios monárquico-liberales y conservadores.

Los redactores se afanaron en poner de manifiesto el ánimo que impulsaba cada publicación. Cualquier vecino de la ciudad que dispusiese de dos reales a la semana y de 8 reales al trimestre fuera de la ciudad podía conocer de cerca el programa político del partido republicano federal:

1. Maquetado a tres columnas y con la utilización de una gran variedad de recursos tipográficos, La Protesta se convirtió en el órgano detractor de los planteamientos del gobierno nacido tras la Revolución. El Partido Democrático Republicano Federal constituía la minoría extrema de la izquierda que junto a la minoría extrema de la derecha -carlistas-neocatólicos y alfonsinos- no perdían ocasión de atacar a la mayoría gobernante, con el objetivo de dificultar la consolidación del régimen. El republicanismo federal era consciente de la debilidad del partido gobernante formado por progresistas, unionistas y demócratas, una mayoría en el seno del cual pronto surgieron desavenencias y los distintos partidos fueron separándose progresivamente, debilitados también por la guerra de Cuba que influyó negativamente en la desaparición de los consumos y las quintas. El nuevo gobierno no satisfizo buena parte de las aspiraciones populares. El ataque sería constante desde el periódico.

2. El nuevo régimen tenía otro talón de Aquiles que fue debilitándolo: la dificultad para encontrar un monarca que ocupara el trono español, lo que facilitó las iniciativas a los republicanos. La prensa republicana supo aprovechar esta circunstancia.

3. Junto al ataque al gobierno nacido de la Revolución y al régimen monárquico por el que el gobierno apuesta, la defensa del ideario del partido. La Protesta sienta las bases de su contenido como publicación ${ }^{5}$.

- El periódico defiende la desaparición de las quintas ${ }^{6}$ y lamenta que no se haya procedido a la abolición de las mismas bajo el sistema liberal ${ }^{7}$. El periódico reprocha al nuevo gobierno su inactividad al respecto ${ }^{8}$ y el incumplimiento por parte del partido liberal en el poder de su promesa programática9. Sobre la abolición de quintas y matrículas de mar, lo mismo que sobre el sufragio universal y los derechos individuales hubo siempre unanimidad de opinión en todas las facciones del partido democrático.

- Son también numerosos los escritos en los que el diario aboga por una Constitución democrática republicana federal, en la que se consignen los principios del partido y las leyes orgánicas municipales, provinciales y electorales; una ley que contempla el jurado y otraa división territorial en lo político, lo administrativo, militar y judicial. La Constitución debería también incluir una ley de organización del partido para evitar anomalías en la elección de representantes para comités locales, provinciales, pactos y asambleas. El periódico no sólo contempla una aspiración republicana sino 
que establece los mecanismos para materializarla. El elector se encuentra ante un ideario político-ideológico, un programa de gobierno.

- La Protesta aboga también por una de las reivindicaciones más anheladas: el establecimiento de la ley del jurado ${ }^{10}$.

El espíritu que inspira la edición del periódico está basado en el respaldo al Partido Republicano Democrático Federal y en la difusión de sus propuestas, así como en el ataque directo al gobierno en el poder - liberales monárquicos progresistas- y a la Constitución monárquica.

La salida del periódico a la calle no puede ser más oportuna ni más efectiva. La Protesta comienza a publicarse, ya lo hemos dicho, en mayo de 1871. Es época de tomar decisiones, demasiadas aspiraciones políticas distintas, demasiados sueños que materializar, demasiado trabajo que realizar en el marco político y en el periodístico.

Cuando las Cortes quedan constituidas, tienen que decidir si el régimen del país ha de ser monárquico o republicano.

Los republicanos no se organizan bien; las masas se sienten sin dirigismo organizado. Caen en el apoliticismo de lo que trata de sacar provecho el anarquismo.

La Protesta, como periódico de partido que se concibe trata de sacar a las masas de ese apoliticismo, de darles a conocer sus principios y convencerlas de que existe una alternativa al gobierno democrático liberal del momento y una alternativa al régimen monárquico. El periódico surge en el momento en que acaba de constituirse la sección española de la Asociación Internacional de Trabajadores a la que se adhieren las masas obreras. Ante el empuje de la AIT, el partido, que ve cómo sus potenciales adeptos se adhieren a otra organización, necesita de un órgano difusor de sus ideas: un periódico, al uso de lo que es característico durante el Sexenio. Pero además los republicanos cuentan con las ventajas de un régimen monárquico muy débil en la figura de Amadeo I de Saboya, conseguido después de mendigar largamente por Europa, un monarca para el trono español y de un gobierno que deja traslucir la división entre los grupos que lo integran. Pese a todo la República no llegaría hasta 1873.

Cuatro números antes de que La Protesta desaparezca se produce una modificación en la redacción del periódico. Con la modificación de la redacción, quizá se trató de matizar la orientación, con el objetivo de que se prolongara la publicación que, finalmente, acabó por desaparecer aunque no hubo tal cambio porque algunos de los nombres que integran la nueva redacción, ya firmaban artículos publicados desde los primeros números de La Protesta ${ }^{11}$.

Un mes más tarde, el periódico desaparecía de la circulación periodística. No sin antes insistir en la línea política que lo caracterizó durante su corta publicación en un último intento de arrastrar a los lectores a una causa común ${ }^{12}$.

Sólo siete meses de vigencia del periódico. La corta duración de La Protesta en la calle no fue una excepción a la suerte que corrieron otras publicaciones republicanas. 
En 1868 se fundaron tres periódico; ninguno de ellos está en la calle en 1869. En este año se fundan 4 nuevas publicaciones de las que en el año 70 sólo queda una, que se suma a los 5 periódicos que salen a la luz pública ese año. El 1871 se registra un incremento en el número de periódicos en circulación. Diez publicaciones de partido circulan por las calles de la ciudad, de los que seis se fundan ese mismo año, por lo que son cuatro las publicaciones que consiguen mantenerse. En 1872 sólo se fundan dos periódicos nuevos, mientras que pueden leerse hasta 8, de los cuales sólo 5 siguen leyéndose en el año 73, en que se funda además uno nuevo. Nninguno de ellos se mantiene en el 74.

Puede afirmarse que la prensa de partido nace y muere en el Sexenio, pero no lo hace sin dejar huella en la historia del periodismo español y castellonense. En los 6 años se fundan en Castellón 21 periódicos de partido, de los que 8 son órganos de expresión del Partido Republicano de la ciudad. Ninguno tiene una vigencia de publicación superior a un año.

Llegados a este punto cabe preguntarnos ¿desaparecen también los partidos cuando la Restauración pone fin al Sexenio? ¿qué pasa con los grupos políticos que surgen a principios del Sexenio?, ¿desaparecen los partidos políticos, desaparecen los órganos de expresión? El Centinela Federal nace en septiembre de 1871 y se publica hasta mayo del 73. Veinte meses de vida saliendo cada semana a las calles de la ciudad castellonense y de la provincia al precio de un real y medio al mes y cuatro al trimestre en Castellón ciudad y a cinco reales al trimestre fuera de la misma. El Centinela Federal sale de la imprenta de González Chermá y nace como órgano oficial del partido republicano, justo un mes antes de que desapareciera La Protesta. Prensa y política se confunden nuevamente bajo la dirección del político y periodista González Chermá. El periódico es creado por el comité del Partido Republicano Federal con el espíritu de publicar artículos sobre reformas esenciales y poner de manifiesto su malestar con el rey Amadeo I. El periódico clama en reiteradas ocasiones contra la naciente monarquía española.

Los republicanos federales conocen la debilidad de la recién proclamada monarquía y la dificultad del monarca para formar gobierno. El Centinela Federal no es ajeno a esta circunstancia y no duda en ponerlo de manifiesto en sus páginas ${ }^{13}$. La concepción que el periódico tiene de la institución y del monarca nos aproxima a la concepción que los republicanos federales tienen del momento ${ }^{14}$.

Defensa de los principios republicanos federales, que es igual a la defensa del ideario del director de la publicación, Francisco González Chermá, quien fue muy activo en política. Fue alcalde de Castellón, durante los primeros años del Sexenio, miembro de la Junta Revolucionaria, miembro destacado del partido republicano castellonense y representante del partido por la provincia en el Pacto de Tortosa -mayo 1869-, en el que se acuerda la defensa de la revolución, se reafirma la aspiración a la República y se establece que la promulgación de la Constitución monárquica no justifica el uso de la fuerza ${ }^{15}$. 
El periódico, que dirigió durante 8 meses, permite una aproximación a su figura y a su obra periodística y política. El Centinela Federal es el escenario y González Chermá el personaje protagonista, bien como periodista, bien como punto de mira en artículos firmados por miembros de la redacción.

La figura de Chermá era polémica; las más de las veces provocaba la ira y la consecuente crítica de sus oponentes políticos y no en vano el director de El Centinela Federal se convirtió en blanco de los ataques de políticos y escritores de tendencias políticas opuestas. Es justamente a través de la defensa que hace el periódico y el propio González Chermá de su persona y de sus actuaciones, como nos aproximamos al concepto que el partido republicano tenía del cabecilla del partido, a su andadura política, a los principios que le inspiraban y al posicionamiento que diario, director y partido tenían respecto a temas que afectaban a la sociedad del momento, al pueblo por el que dice entregarse sin reservas ${ }^{16}$.

\section{El periódico: él y sus circunstancias. Historia de la aparición y desaparición de la prensa}

Las circunstancias políticas subyacen bajo la publicación de periódicos antes, durante y después del Sexenio. El carácter de los periódicos y su línea editorial está en función del grado de libertad otorgado por los gobiernos del momento y de las restricciones impuestas al libre ejercicio de la imprenta.

El marco político tiene su traducción periodística; el periódico es un instrumento de acción social tendente a perpetuar o a cambiar las circunstancias políticas y sociales existentes en cada momento histórico. 1868-1874 es época de ruptura; es el momento de la prensa republicana y progresista que reivindica, denuncia, satiriza y combate con la pluma. En la que se buscan y encuentran consignas disfrazadas, ambiciosos sueños y libertades insatisfechas, espíritu de lucha y el siguiente paso: las restricciones, la censura.

Desde que se inicia el Sexenio, la prensa va adquiriendo mayores cotas de libertad que se verán truncadas por las circunstancias políticas. La permisividad conquistada en el ámbito periodístico se enmarca en un período caracterizado por la consecución de algunas libertades, que dejaron su huella en el marco político, socio-económico y jurídico.

En 1870 El Radical informa sobre el proyecto de ley presentado a las Cortes para la abolición de la pena de argolla. Junto a este proyecto de ley otros muchos: proyecto de ley sobre los medios de cubrir los presupuestos provinciales y municipales; sobre la reincorporación al Estado de los oficios de la fé publica enajenados por la Corona y provisión de notarías; sobre los efectos civiles de la pena de interdicción ${ }^{17}$; sobre la elección del monarca, sobre la construcción de obras de agua ${ }^{18} \ldots$ 
Las numerosas disposiciones y proyectos de ley que se publican ponen de manifiesto que el Sexenio es una época de actividad política, de cambios, de reformas... tendentes a incrementar las cotas de libertad de los ciudadanos. La prensa no es una excepción. Se respira el ánimo de introducir propuestas hechas a las Cortes, las más de las veces presentadas, las menos, materializadas en toda su extensión.

Y junto a las propuestas y proyectos, las circulares enviadas por las distintas administraciones públicas ${ }^{19}$.

Las leyes y normas que se publican tienden a proteger y garantizar los derechos de los ciudadanos ${ }^{20}$.

En marzo de 1870, las Cortes Constituyentes aprueban una proposición de ley que suprime la pena de muerte impuesta por el Código Penal a los reos de delito de rebelión y es sustituida por la cadena perpetua ${ }^{21}$.

Los periódicos escriben páginas y páginas sobre reformas propuestas en distintos ámbitos, reflejo de la efervescencia política desde la tribuna y desde la prensa por conseguir libertades inexistentes en épocas anteriores.

Hay euforia legislativa, de movimiento y cambio en el ámbito social y euforia, movimiento y cambio en el ámbito periodístico. Y se pone de manifiesto en la gran proliferación de publicaciones periódicas que se produce con el Sexenio Revolucionario; en esta época, el periódico nace y muere de partido.

Es en este contexto en el que nace el periódico de partido, portavoz de ideas, transmisor de ideologías. Y es en este contexto en el que la censura subyace bajo las publicaciones que salen a la calle a principios de los años $70^{22}$.

El Centinela Federal da a conocer la desaparición de El Farol y alude a cuestiones que responden a la censura de la época.

En numerosas ocasiones, el periódico de González Chermá pone de manifiesto que la prensa no disfrutaba de la libertad pretendida, aunque reconoce cierta libertad de expresión de ideas. Esto, no obstaba a que los escritores fuesen víctimas de procesos y penas inclusive la privacidad de la libertad ${ }^{23}$.

Las referencias a la falta de libertades en el ámbito de la prensa se suceden insertas en los distintos artículos, aunque nunca se hace un ataque frontal a la situación periodística. Pese a que la censura era un hecho de la época, los periódicos informaban en sus páginas sobre las restricciones, los registros y las denuncias que afectaban a las distintas redacciones y a las propias publicaciones escritas ${ }^{24}$.

A pesar de las restricciones que los periódicos republicanos denuncian existe la libertad suficiente para ponerlo de manifiesto en artículos en los que se denuncia la falta de libertad de imprenta ${ }^{25}$.

El nacimiento y la desaparición de los periódicos republicanos así como la efímera existencia de los mismos no es casual. Las circunstancias marcan la vida de unas publicaciones que nacen y mueren con el partido político. 
La primera referencia que se hace a la libertad de prensa la encontramos en el discurso que realiza el radical Nicolás María Rivero en las Cortes, enmarcado en el programa de gobierno que presenta el gabinete ministerial constituido en enero de 1871 sobre la base Prim-Rivero.

Las convulsiones políticas, las múltiples escisiones y los pactos, a veces contra natura, de los partidos existentes, provocaron los consiguientes vaivenes periodísticos. Los textos extraídos de las publicaciones analizadas, ponen de manifiesto la existencia de una libertad de prensa cuestionable y relativa. Los motivos de la aparición y desaparición de los periódicos, así como la existencia efímera de los mismos, cabe en la multiplicidad de corrientes políticas que proliferan a partir de la Revolución Gloriosa.

Proclamada la Revolución pronto aparecen las primeras fisuras en los partidos. Tras la aprobación de la Constitución del 69 -que puede considerarse como la primera Constitución democrática de la historia española-, las Cortes aprueban una amplia legislación para acomodar las instituciones a los principios del texto constitucional. Pero la consolidación del sistema debían llevarla a cabo los grupos políticos y pronto se puso de manifiesto su incapacidad para constituir una alianza de gobierno duradera. Progresistas, unionistas y demócratas monárquicos, que habían formado la mayoría, fueron separándose. Al tiempo, las minorías extremas -carlistas neocatólicos y alfonsinos y republicanos federales-, atacaron a la mayoría y dificultaron la consolidación del régimen.

Las discrepancias interrepublicanas provocan la aparición de multitud de periódicos. La inestabilidad de la prensa republicana revela el conflicto que se produce en el seno de esta organización. A finales de 1869 la división era obvia también en las filas del partido liberal monárquico. La unión que se produjo en defensa de la Revolución duró poco. Las diferencias entre progresistas, unionistas y demócratas pronto aparecieron de nuevo ${ }^{26}$. Desde la prensa se critica la pasividad monárquico-democrática ${ }^{27}$. Las divisiones en el seno del partido republicano se evidenciaron también en el Sexenio. Cuando se proclama la República los republicanos están fuertemente divididos: ante la extensión de las medidas sociales, y entre benévolos e intransigentes por la forma de construir la federación. Mientras unos exigían la inmediata proclamación del federalismo, la dirección del partido deseaba realizarla democráticamente en la nueva Constituyente. En Castellón ciudad nos encontramos, a principios de los años 70, con un Partido Liberal Monárquico dividido en progresistas, unionistas y demócratas; un partido republicano con una corriente interna que apuesta por el federalismo; un partido radical a medio camino entre progresistas y republicanos; un partido carlista y el partido conservador. La proliferación de grupos políticos conlleva una intensa proliferación periodística. Dado que los partidos políticos no se conciben sin un órgano de expresión, cada grupo político tiene en la calle un altavoz de sus principios. Durante el Sexenio, los monárquicos-liberales dispusieron de siete publicaciones periódicas. 


\section{Conclusiones}

La prensa de partido nace en el Sexenio Democrático Hasta esta fecha no había aparecido prensa vinculada a un partido político. Es un hecho nuevo, desconocido y emergente. La prensa durante el Sexenio es prensa de partido, o no es. Está plenamente imbricada con el partido político. La simbiosis entre la estructura de partido político y la prensa está patente en todas y cada una de las líneas escritas en letra de molde.

Cualquier pretensión de independencia resulta ser una declaración de intenciones, pero la realidad es que el partido es la médula espinal del periódico, sin la cual dejaría de existir. La realidad social, económica y política que se transmite en la prensa está tamizada por el ideario del partido que la crea y por los actores que la protagonizan, que son políticos y redactores. El periódico es un instrumento para influir en los ciudadanos, como una incipiente, de lo que ahora daríamos en llamar, arma electoral.

\section{Bibliografía}

ARTOLA, M.: Partidos y programas politicos, Edi. Alianza. 1991.

CORONA, C.: Algunes dades al voltant de F.González Chermá, polític i periodista, Edi. Diputació de Castelló.

FAUS, J.: La Revolución de 1868. Las juntas revolucionarias de Castellón, 30 Septiembre- 23 Octubre 1868, Edi. BSCC. 1968. t LXII/n.

HERRAIZ, J.L. Y REDÓ, P.: Republicanisme i valencianisme (1868-1938), Edi. UJI. 1995.

MARTÍ,M.: Aproximació al personal polític castellonenc a finals del segle XIX, Edi. BSCC. 1990. $\mathrm{N}^{\mathrm{o}} 66$.

MARTíNEZ GALLEGO, F.: Prensa y partido en el progresismo valenciano. José Peris y Valero (1821-1876), Edi. Ateneu de periodistas, 1994.

MONLLEÓ, R.: Castellón durante el Sexenio, Edi. BSCC.1983. no 59.

MONLLEÓ, R.: Los diputados valencianos en la I República: Federalismo y levantamiento carlista en las comarcas de Castelló, Edi. Diputación de Castellón. Servei de Publicacions. 1996. Castellón.

MONLLEÓ, R.: Republicanos contra monárquicos: del enfrentamiento electoral y parlamentario a la insurrección federal de 1869, Edi. BSCC. 2001.

ORDERIA, E.: Historia de la comunicación social

PIQUERAS, J.A. Y CHUST, M.: República y republicanos en España, Edi. s.XXI.

VICENTE, A.M.: Grups politics i clase dirigent a Castelló de la Plana (1850-1875)Introducció a un estudi d'història local, Edi. Congrés d'Estudis d'Història de la Plana. 1987.

VIVIANO, P.: Catàleg bibliogràfic de les publicacions periòdiques de Castelló (1838-1874), Edi.Centre d'Estudis de la Plana. 1986. № 8. 


\section{Notas}

1 El Centinela Federal, 6 septiembre 1871

2 La Protesta, 14 mayo 1871

3 La Justicia, 10 octubre 1873

4 Viciano i Navarro, P.: op, Cit, pág 67

5 La Protesta, 14 junio 1871

6 La Protesta, 14 mayo 1871

7 La Protesta, 24 julio 1871

8 La Protesta, 24 julio 1871

9 La Protesta, 10 septiembre 1871

${ }^{10}$ La Protesta, 4 junio 1871

${ }^{11}$ La Protesta, 29 octubre 1871

12 La Protesta, 29 octubre 1871

13 El Centinela Federal, 22 octubre 1871

${ }^{14}$ El Centinela Federal, 29 octubre 1871

15 Piqueras Arenas, J.A.: La Revolución Democrática (1868-1874). Cuestión social, colonialismo y grupos de presión, pág 86

16 El Centinela Federal, 15 octubre 1871

17 El Radical, 4 enero 1870

18 El Radical, 30 enero 1870

19 El Radical, 1 febrero 1870

${ }^{20}$ El Radical, 1 febrero 1870

21 El Radical, 6 marzo 1870

22 El Radical, 9 febrero 1870

${ }^{23}$ El Centinela Federal, 17 marzo 1872

${ }^{24}$ El Centinela Federal, 31 marzo 1872

${ }^{25}$ El Centinela Federal, 31 marzo 1872

${ }^{26}$ El Radical, 2 enero 1870

${ }^{27}$ El Radical, 2 enero 1870 